\title{
PERAN PENGELOLA RADIO KOMUNITAS DALAM MENGEMBANGKAN SIARAN KEARIFAN LOKAL
}

\author{
Neti Sumiati Hasandinata \\ Balai Pengkajian dan Pengembangan Komunikasi dan Informatika \\ Jln.Pajajaran No. 88 Bandung, Jawa Barat - 40173, Telp. 022-6017493, Fax. 022-6021740, HP. 0811220846. \\ Email: hanetihasan@gmail.com \\ Naskah diterima tanggal 30 Oktober 2014, direvisi tanggal 18 November 2014, disetujui tanggal 27 November \\ 2014
}

\section{MANAGEMENT ROLE OF COMMUNITY RADIO IN LOCAL WISDOM BROADCAST DEVELOPING}

\begin{abstract}
Facing the wave of globalization, community radio as broadcast industry with local content, are required awareness to increase local wisdom in every aspect of life particularly culture aspect. Therefore management of community radio need to understand local wisdom for implemented in packaging content. The problem is how management of community radio in developing local wisdom broadcast, the purpose of this research is to find out the role of community radio management in development local wisdom broadcast. This research is qualitative, purposively informan selection, data collection technique by interview, observation, and documentation. The result show that the role of community radio management in developing local wisdom broadcast is realized in form of local wisdom broadcast in community radio is the featured broadcast program. Programs and broadcasts local wisdom in the form of the local culture, manifested through broadcast programs compiled and presented in a packed agenda that creatively with interactive concept.
\end{abstract}

Keywords: management role, Community Radio, local wisdom broadcast development.

\begin{abstract}
Abstrak
Menghadapi arus globalisasi, Radio Komunitas sebagai industri penyiaran yang berkonten lokal, dituntut kepedulian meningkatkan kearifan lokal dalam berbagai aspek kehidupan khususnya aspek budaya. Karena itu pengelola Radio Komunitas perlu memahami kearifan lokal untuk diimplementasikan dalam mengemas isi siaran. Permasalahannya adalah bagaimana peran pengelola Radio Komunitas dalam mengembangkan siaran kearifan lokal, tujuan penelitian ini adalah ingin mengetahui peran pengelola Radio Komunitas dalam mengembangkan siaran kearifan lokal. Penelitian ini bersifat deskriptif kualitatif, penentuan informan dilakukan secara purposif, teknik pengumpulan data dilakukan dengan wawancara, observasi, dan dokumentasi. Hasil penelitian menunjukkan bahwa peran pengelola Radio Komunitas dalam mengembangkan siaran kearifan lokal penelitian ini diwujudkan dalam bentuk program-program siaran di Radio Komunitas yang merupakan program siaran unggulan. Program dan bentuk siaran kearifan lokal dalam mengangkat budaya lokal, diwujudkan melalui program siaran yang disusun dan disajikan dalam suatu mata acara yang dikemas secara kreatif dengan konsep interaktif.
\end{abstract}

Kata kunci: peran pengelola, Radio Komunitas, pengembangan siaran kearifan lokal. 


\section{PENDAHULUAN}

Keberadaan Radio Komunitas, menjadi salah satu alternatif pemerataan arus informasi, sebagai sarana interaksi sosial, pemenuhan aspirasi politik, pada lingkup perkotaan dan perdesaan. Wacana Radio Komunitas di Indonesia dikenal sejak dimulainya advokasi untuk merevisi UU No. 24 Tahun 1997 tentang Penyiaran. Dua hal yang menjadi dasar rasional kehadiran radio komunitas adalah: Pertama, keyakinan radio komunitas di masyarakat akan mengukuhkan frekuensi sebagai ranah publik (public domain) yang terbuka bagi siapapun. Radio Komunitas menghapus monopoli penggunaan frekuensi hanya oleh pengelola radio swasta dan radio milik pemerintah (penggunaan istilah radio swasta dan radio pemerintah diatur dalam UU No. 24 Tahun 1997 tentang Penyiaran yang kemudian direvisi dalam UU No. 32 Tahun 2002 tentang Penyiaran). Kedua, munculnya radio yang dioperasikan oleh dan berbasis komunitas diyakini dapat memulihkan persepsi buruk radio di era rezim Orde Baru yang identik sebagai alat propaganda penguasa (Masduki, 2004). Lahirnya Radio Komunitas di berbagai daerah saat ini, menunjukkan adanya kesadaran dan keinginan dari masyarakat akan informasi dan komunikasi di tingkat lokal. Karena media massa mainstream saat ini lebih menomorsatukan peristiwa-peristiwa berskala besar dan nasional daripada potret sosial kemasyarakatan yang bersifat lokal (Lilis dan Yuliati, 2012).

Sebagai salah satu bagian dari sistem penyiaran, Radio Komunitas berpartisipasi dalam penyampaian informasi yang dibutuhkan komunitasnya, baik yang menyangkut aspirasi warga, program pemerintah juga menggali dan mengembangkan potensi lokal yang ada di lingkungannya. Lilis dan Yuliati (2012) mengatakan bahwa secara sederhana Radio Komunitas diartikan sebagai radio dari, oleh, untuk, dan tentang komunitas. Radio ini menjadikan komunitas sebagai basis operasionalisasi radio, karena menonjolkan lokalitas maka proses produksi dan program acara di masing-masing Radio Komunitas cenderung berbeda satu sama lain. Tujuan Radio Komunitas sebagaimana disebutkan dalam Pasal 21 ayat 2 huruf b UndangUndang No. 32 Tahun 2002, tentang Penyiaran dimaksudkan untuk mendidik dan memajukan masyarakat dalam mencapai kesejahteraan dengan melaksanakan program acara yang meliputi budaya, pendidikan, dan informasi yang menggambarkan identitas bangsa. Ketentuan program siaran, idealnya sesuai dengan ruh/semangat pendirian Radio Komunitas. Untuk itu, informasi yang disajikan harus menyentuh kebutuhan komunitasnya. Prinsip proximitas atau kedekatan psikologis (fisik dan budaya) antara radio dengan warganya menjadi komponen utama kelebihan Radio Komunitas dibanding jenis radio lainnya (Rachmiatie, 2007).

Radio Komunitas sebagai industri yang berkonten lokal, menuntut warganya atau komunitasnya untuk berperan aktif dan peduli dalam mengangkat potensi dan kearifan lokal sesuai dengan nilai-nilai lokal dalam berbagai aspek kehidupan. Keberadaan kearifan lokal merupakan hasil dari proses adaptasi turun temurun dalam periode waktu yang sangat lama terhadap suatu lingkungan yang biasanya didiami ataupun lingkungan di mana sering terjadi interaksi di dalamnya. Kearifan lokal sendiri merupakan tata nilai kehidupan yang terwarisi dari satu generasi ke generasi berikutnya yang berbentuk religi, budaya, ataupun adat istiadat yang umumnya ber bentuk lisan dalam suatu sistem sosial di masyarakat (Juniarta, dkk, 2013). Kearifan lokal baru menjadi wacana dalam masyarakat tahun 1980-an, ketika nilai-nilai budaya lokal yang terdapat dalam masyarakat Indonesia sebagai warisan nenek moyang sudah hampir habis digerus arus modernisasi, yang membuka diri kepada globalisasi, dengan demikian kekayaan budaya lokal, baik berupa kesenian, sastra, hukum adat, diperkirakan sebagai penyebab punahnya budaya nasional (Rosidi, 2011).

Saat ini Radio Komunitas semakin memantapkan perannya dalam proses pembentukkan dan menguatkan potensi lokal, menyokong ekonomi kerakyatan, dan melestarikan kearifan lokal sekaligus 
mendorong terwujudnya aparat yang bersih (Hakam, 2011). Begitu pentingnya eksistensi Radio Komunitas, terutama untuk mengembangkan siaran yang bernuansa kearifan lokal, maka penulis melakukan penelitian yang berjudul "Peran Pengelola Radio Komunitas dalam Mengembangkan Siaran Kearifan Lokal". Permasalahan yang diangkat dalam penelitian ini adalah bagaimana peran pengelola Radio Komunitas dalam mengembangkan siaran kearifan lokal? Adapun tujuan dari penelitian ini adalah ingin mengetahui dan mengkaji mengenai peran pengelola Radio Komunitas dalam mengembangkan siaran kearifan lokal. Penelitian ini, diharapkan menjadi data awal bagi pemerintah dalam hal ini Kementerian Komunikasi dan Informatika ataupun Pemerintah Provinsi Jawa Barat dalam menentukan kebijakan untuk pengembangan penyebaran informasi yang efektif dan tepat sasaran serta memelihara kearifan lokal untuk membentuk insan yang berkarakter berbudi luhur dalam menghadapi tantangan globalisasi.

\section{LANDASAN KONSEP}

\section{Penelitian Terdahulu}

Ada beberapa penelitian terdahulu mengenai Radio Komunitas yang menyajikan siaran kearifan lokal. Perbedaan dari beberapa penelitian tersebut dengan penelitian yang penulis susun saat ini terlihat pada tabel 1 .

\section{Peran Pengelola Radio Komunitas dalam Mengembangkan Siaran Kearifan Lokal}

Radio adalah media massa yang dikembangkan oleh Macroni yang didemonstrasikan di The New Time pada tahun 1901, kemudian digunakan pada tahun 1920. Radio kini telah menjadi instrumen sosial yang unik dan merupakan medium yang amat penting (Anwari, 2013). Arifin (1993), mengatakan bahwa radio merupakan alat komunikasi dalam arti saluran pernyataan manusia yang umum, terbuka, dan menyalurkan lambang-lambang berbunyi berupa program yang teratur yang isinya aktual dan meliputi segala segi perwujudan alam kehidupan manusia. Seiring dengan perkembangan zaman, maka kebutuhan informasi masyarakat semakin bertambah, terutama informasi-informasi yang bersifat lokal, yang selama ini tidak mereka dapatkan dari radio konvensional. Oleh karena itu saat ini mulai bermunculan Radio Komunitas di berbagai daerah, yang salah satu tujuannya adalah mengangkat potensi dan kearifan lokal yang ada di daerah masing-masing. Dengan berdirinya Radio Komunitas maka masyarakat juga diajak berperan aktif untuk mengembangkan Radio Komunitas. Radio Komunitas sendiri dapat diartikan sebagai lembaga layanan nirlaba yang dimiliki dan dikelola oleh komunitas tertentu umumnya melalui yayasan atau asosiasi. Tujuannya adalah untuk melayani dan memberikan manfaat kepada komunitas di mana lembaga penyiaran tersebut berada (Fraser dan Estrada, 2001).

Radio Komunitas memiliki isi program siaran dan informasi yang bersifat khas dan tertentu, dan dapat menggarap permasalahan spesifik di sebuah lingkungan terbatas, baik segi-segi yang menyangkut hiburan, pendidikan, maupun informasi. Radio Komunitas adalah medium yang memungkinkan masyarakat dalam lingkungan terbatas, mengaktualisasikan dirinya melalui program yang dikelola secara bersama-sama (Wibowo, 2012).

Stasiun penyiaran komunitas dalam UU No. 32 Tahun 2002 tentang Penyiaran, pasal 21 disebutkan bahwa lembaga penyiaran yang berbentuk badan hukum Indonesia, didirikan oleh komunitas tertentu, bersifat independen dan tidak komersial dengan daya pancar rendah, luas jangkauan wilayahnya terbatas, serta untuk melayani kepentingan komunitasnya. Radio Komunitas merupakan stasiun penyiaran radio yang didirikan oleh dan untuk komunitas tertentu, yang tidak bersifat komersial dan muatannya sebagian besar tentang dinamika dan kebutuhan komunitas itu sendiri (Sudibyo 2004). Secara umum, Radio Komunitas adalah dari komunitas, oleh komunitas, untuk komunitas, dan tentang komunitas. UNESCO mendefinisikannya sebagai berikut: Community Radio is a type of radio service 
that caters to the interests of a certain area, broadcasting content that is popular to a local audience but which may often be overlooked by commercial or mass-media broadcasters (Radio Komunitas adalah jenis layanan radio yang melayani kepentingan daerah tertentu, konten penyiaran yang populer ke khalayak lokal tapi yang

Tabel 1

\section{Perbedaan Penelitian Peran Pengelola Radio Komunitas dalam Mengembangkan Siaran Kearifan Lokal dengan Penelitian Terdahulu}

\begin{tabular}{|c|c|c|c|}
\hline & \multicolumn{3}{|c|}{ Judul Penelitian } \\
\hline & $\begin{array}{c}\text { Kajian Mengusung Radio } \\
\text { Komunitas sebagai Basis } \\
\text { Kearifan Lokal }\end{array}$ & $\begin{array}{c}\text { Prediksi Perkembangan } \\
\text { Radio Komunitas (Studi } \\
\text { faktor-faktor yang } \\
\text { memengaruhi perkembangan } \\
\text { Radio Komunitas di } \\
\text { Yogyakarta dan Solo) }\end{array}$ & $\begin{array}{c}\text { Peran Pengelola Radio } \\
\text { Komunitas dalam } \\
\text { Mengembangkan Siaran } \\
\text { Kearifan Lokal }\end{array}$ \\
\hline Penulis & $\begin{array}{c}\text { Dede Lilis Ch dan Nova } \\
\text { Yuliati }\end{array}$ & Ifa Rizty Fauzia & Neti Sumiaty Hasandinata \\
\hline Deskripsi & Meskipun keberadaan Radio & Di tengah maraknya radio & Menghadapi arus globalisasi \\
\hline Penelitian & $\begin{array}{l}\text { Komunitas saat ini karut marut } \\
\text { karena belum ada regulasi yang } \\
\text { menaunginya, namun geliat } \\
\text { pertumbuhannya tidak pernah } \\
\text { surut, karena radio komunitas } \\
\text { lahir untuk memenuhi } \\
\text { kebutuhan informasi masyarakat } \\
\text { lokal/komunitas yang } \\
\text { mengangkat isu-isu lokal. Hal } \\
\text { tersebut tidak mereka dapatkan } \\
\text { pada media massa mainstream. } \\
\text { Sehingga tidak bisa dipungkiri, } \\
\text { Radio Komunitas bisa } \\
\text { merepresentasikan dan } \\
\text { mempromosikan masyarakat } \\
\text { madani (civil society) dengan } \\
\text { muatan budaya dan identitas } \\
\text { yang berbasis kearifan lokal. }\end{array}$ & $\begin{array}{l}\text { komersil yang berusaha meraup } \\
\text { keuntungan besar, justru } \\
\text { muncul Radio Komunitas non } \\
\text { komersil sebagai wadah untuk } \\
\text { menyampaikan aspirasi dan } \\
\text { apresiasi dari anggota } \\
\text { komunitasnya. Keberadaan } \\
\text { Radio Komunitas ini membawa } \\
\text { angin segar bagi masyarakat } \\
\text { untuk mengapresiasikan ide } \\
\text { maupun pendapatnya. Namun } \\
\text { Radio Komunitas ini masih } \\
\text { memiliki banyak permasalahan } \\
\text { yang harus diselesaikan. }\end{array}$ & $\begin{array}{l}\text { Radio Komunitas sebagai } \\
\text { industri penyiaran } \\
\text { berkonten lokal, dituntut } \\
\text { kepeduliannya } \\
\text { meningkatkan kearifan lokal } \\
\text { dalam berbagai } \\
\text { kehidupan khususnya aspek } \\
\text { budaya. Karena itu pengelola } \\
\text { Radio Komunitas perlu } \\
\text { memahami kearifan lokal } \\
\text { untuk diimplementasikan } \\
\text { dalam mengemas isi siaran. }\end{array}$ \\
\hline $\begin{array}{l}\text { Fokus } \\
\text { Penelitian }\end{array}$ & $\begin{array}{l}\text { Sepak terjang radio komunitas } \\
\text { dalam mewujudkan masyarakat } \\
\text { madani melalui peran aktifnya } \\
\text { menanamkan nilai-nilai kearifan } \\
\text { lokal. }\end{array}$ & $\begin{array}{l}\text { Masa depan Radio Komunitas } \\
\text { dalam kurun waktu }-5,-10 \text {, dan } \\
15 \text { tahun ke depan. }\end{array}$ & $\begin{array}{ll}\text { Peran pengelola } & \text { Radio } \\
\text { Komunitas } & \text { dalam } \\
\text { mengembangkan } & \text { siaran } \\
\text { kearifan lokal } & \end{array}$ \\
\hline $\begin{array}{l}\text { Tujuan } \\
\text { Penelitian }\end{array}$ & $\begin{array}{l}\text { Mengkaji Sepak terjang radio } \\
\text { komunitas khususnya di } \\
\text { Kabupaten Bandung dalam } \\
\text { mewujudkan masyarakat } \\
\text { madani melalui peran aktifnya } \\
\text { menanamkan nilai-nilai kearifan } \\
\text { lokal. }\end{array}$ & $\begin{array}{l}\text { Ingin mengetahui mengenai } \\
\text { masa depan Radio Komunitas } \\
\text { dalam kurun waktu }-5,-10 \text {, dan } \\
15 \text { tahun ke depan. }\end{array}$ & $\begin{array}{l}\text { Mengetahui peran pengelola } \\
\text { Radio Komunitas dalam } \\
\text { mengembangkan } \\
\text { kearifan lokal. }\end{array}$ \\
\hline $\begin{array}{l}\text { Pendekatan } \\
\text { Penelitian }\end{array}$ & Deskriptif & Kualitatif & Deskriptif \\
\hline $\begin{array}{l}\text { Teknik } \\
\text { Pengumpulan } \\
\text { data }\end{array}$ & $\begin{array}{l}\text { Studi dokumentasi dari berbagai } \\
\text { sumber. }\end{array}$ & $\begin{array}{l}\text { Metode studi Delphi yakni } \\
\text { dengan melakukan wawancara } \\
\text { dengan pengelola Radio } \\
\text { Komunitas. }\end{array}$ & $\begin{array}{l}\text { Wawancara mendalam dengan } \\
\text { informan dan observasi. }\end{array}$ \\
\hline
\end{tabular}

Sumber: diolah dari berbagai sumber. 
mungkin sering diabaikan oleh lembaga penyiaran komersial atau media massa).

Menurut Uki Hastama dari Asosiasi Televisi Swasta Indonesia, bahwa muatan lokal atau konten lokal adalah: Pertama, muatan lokal yang memunyai unsur kedekatan (proximity) dengan pemirsa lokal. Kriteria yang harus dimiliki oleh program lokal adalah bersumber dari daerah yang bersangkutan baik ide, karakter, maupun tokoh. Kedua, kemasan (packaging) mencerminkan budaya setempat. Ketiga, program lokal harus memuat atau menggambarkan fakta, seni, atau nilai-nilai lokal baik untuk program berita maupun non berita (Mumpuni, 2011). Kearifan lokal atau juga biasa disebut dengan local wisdom dapat dipahami sebagai usaha manusia dengan menggunakan akal budinya (kognisi) untuk bertindak dan bersikap terhadap sesuatu, objek, atau peristiwa yang terjadi dalam ruang tertentu (Nurhidayah, 2011). Dapat dikatakan bahwa kearifan lokal merupakan konstruksi dari budaya, menurut Haba dalam Abdullah (2008), bahwa kearifan lokal mengacu pada berbagai kekayaan budaya yang tumbuh dan berkembang dalam sebuah masyarakat dikenal, dipercayai, dan diakui sebagai elemen-elemen penting yang mampu mempertebal kohesi sosial di antara warga masyarakat (Nurhidayah, 2011).

Berdasarkan uraian mengenai kearifan lokal tersebut, maka dapat dikatakan bahwa siaran kearifan lokal adalah siaran yang mengacu dan berisi berbagai kekayaan budaya yang ada pada masyarakat setempat. Dalam penelitian ini yang bisa diangkat adalah budaya Sunda karena lokasi Radio Komunitas berada di tatar Sunda, jadi siarannya juga mengacu pada budaya Sunda. Pengelola Radio Komunitas dalam hal ini sangat berperan dalam mengembangkan siaran kearifan lokal, jika sebelumnya sudah ada, ke depan tampaknya siaran kearifan lokal bisa dikembangkan sesuai dengan kearifan lokal yang ada di masing-masing wilayah. Haba, menginventarisir fungsi dan signifikansi dari kearifan lokal sebagai berikut:

1. Sebagai penanda identitas sebuah komunitas;
2. Elemen perekat (kohesif) lintas warga, lintas agama, dan kepercayaan;

3. Kearifan lokal tidak bersifat memaksa atau dari atas (top down), tetapi sebuah unsur kultural yang ada dan hidup dalam masyarakat, karena itu daya ikatnya lebih mengena dan bertahan;

4. Kearifan lokal memberikan warna kebersamaan bagi sebuah komunitas;

5. Local wisdom akan mengubah pola pikir dan hubungan timbal balik individu dan kelompok dengan meletakkannya di atas common ground/kebudayaan yang dimiliki;

6. Kearifan lokal dapat berfungsi mendorong terbangunnya kebersamaan, apresiasi sekaligus sebagai sebuah mekanisme bersama untuk menepis berbagai kemungkinan yang meredusir, bahkan merusak, solidaritas komunal yang dipercayai berasal dan tumbuh di atas kesadaran bersama dari sebuah komunitas terintegrasi (Nurhidayah, 2011).

\section{METODE PENELITIAN}

Penelitian ini bersifat deskriptif kualitatif, Nazir (2009) mengatakan metode deskriptif adalah suatu metode dalam meneliti status sekelompok manusia, suatu objek, suatu kondisi, suatu sistem pemikiran, ataupun suatu peristiwa pada masa sekarang. Tujuan dari penelitian deskriptif ini adalah untuk membuat deskripsi, gambaran atau lukisan secara sistematis, faktual, dan akurat mengenai fakta-fakta, sifat-sifat serta hubungan antarfenomena yang diselidiki.

Dalam penelitian ini informan ditentukan dengan menggunakan teknik purposive sampling (pengambilan sampel berdasarkan tujuan). Informan yang dipilih dengan teknik purposive sampling didasarkan atas pertimbangan :

1. Informan tercatat sebagai pengelola Radio Komunitas;

2. Kesediaan informan untuk diwawancarai oleh penulis.

3. Kemampuan informan dalam memberikan informasi yang relevan dengan latar belakang penelitian. 
Informan dalam penelitian ini seperti terlihat pada tabel 2. Pengumpulan data dalam penelitian ini dilakukan secara seksama dengan pemilihan atau penentuan data dan informasi yang dipandang representatif dalam kerangka holistik. Dalam penelitian ini untuk mendapatkan dan mengumpulkan data dari informan, penulis melakukan dengan pengamatan atau observasi langsung tentang keberadaan Radio Komunitas dan perangkat nya serta wawancara mendalam (depth interview). Studi dokumentasi dilakukan untuk memeroleh data dan informasi sekunder sebagai penunjang penelitian.
Data yang diperoleh kemudian diolah, dianalisis, dan diproses lebih lanjut. Data yang berhasil penulis kumpulkan dari lapangan kemudian ditabulasi dan dianalisis secara deskriptif kualitatif, lalu disajikan dalam bentuk naratif sesuai dengan masalah yang sedang dibahas. keterlibatan mereka dalam seluruh aspek manajemen dan produksi programnya, serta menyajikan program yang membantu mereka dalam pembangunan dan kemajuan sosial di komunitas mereka. Tabel 3 memerlihatkan profil dari Radio Komunitas yang menjadi sampel penelitian.

Tabel 2

Informan Penelitian

\begin{tabular}{|c|c|c|}
\hline No & Nama Informan & Jabatan \\
\hline 1. & H. Asep Bobi & $\begin{array}{l}\text { Pengelola Radio Komunitas Zhara } \\
\text { Setia Tanjungsari, Sumedang. }\end{array}$ \\
\hline 2. & Dian Fardian & $\begin{array}{l}\text { Pengelola Radio Komunitas STIMIK UNSAP Jl. Anggrek Situ, } \\
\text { Sumedang. }\end{array}$ \\
\hline 3. & Drs. Dadang Setiawan S.Ag & $\begin{array}{l}\text { Pengelola Radio Komunitas Cahya Swara Giwangkara SMK } \\
\text { Muhamadiyah J1. Dano Sumedang. }\end{array}$ \\
\hline 4. & Ir. Nanang Nurasa & $\begin{array}{l}\text { Pengelola Radio Komunitas Sungging Galura Rasa Desa Cilangkap Buah } \\
\text { Dua, Sumedang. }\end{array}$ \\
\hline 5. & $\begin{array}{l}\text { Dr. Nuroni Hidayat } \\
\text { Soeriadikusumah }\end{array}$ & Pengelola Radio Komunitas Gentra Pakuwon, Jl. Rd. Suyud, Sumedang. \\
\hline 6. & Udin Sutisna & Penyiar Radio Komunitas Zhara Setia Tanjungsari, Sumedang \\
\hline 7. & Recky Junaedi & Penyiar Radio Komunitas STIMIK UNSAP Jl. Anggrek, Sumedang. \\
\hline 8. & Wawan Gunawan/Dedi Mulyadi & $\begin{array}{l}\text { Penyiar Radio Komunitas Cahya Swara Giwangkara SMK Muhamadiyah } \\
\text { Jl. Dano, Sumedang. }\end{array}$ \\
\hline & Yaya/Engkus & $\begin{array}{l}\text { Penyiar Radio Komunitas Sungging Galura Rasa Desa Cilangkap Buah } \\
\text { Dua, Sumedang. }\end{array}$ \\
\hline 10. & Ii Ratiah/Cecep & Penyiar Radio Komunitas Gentra Pakuwon Jl. Rd. Suyud, Sumedang. \\
\hline
\end{tabular}

Sumber: hasil wawancara 2013.

\section{HASIL PENELITIAN DAN PEMBAHASAN}

\section{Dinamika Radio Komunitas di Kabupaten Sumedang}

Perkembangan Radio Komunitas di Kabupaten Sumedang cukup pesat. Hampir di setiap kecamatan terdapat Radio Komunitas. Ada yang masih uji coba masa pengenalan dengan memutar lagu-lagu lokal, pop Sunda, memutar kaset wayang dan menyampaikan informasi ringan, menampilkan identitas komunitas. Ada pula yang sudah masa pemantapan program melaksanakan siaran rutin komunitas, yang sudah pencapaian target pendengar, dan mengikuti prosedur perizinan, meningkat pada pesan-pesan kemasyarakatan yang berhubungan dengan kepentingan masyarakat di wilayahnya, serta mulai berinteraktif dengan warganya, menjadi perekat keakraban antarwarganya.

Partisipasi dan keterlibatan warga cukup menggembirakan, ditandai adanya paket budaya, kerjasama warga, dapat saling interaksi di udara, yang semula biasa 
dilakukan di masjid atau di balai desa sekarang dapat dilakukan melalui radio. Hal ini juga memerlihatkan ciri khas dari Radio Komunitas, seperti yang dikatakan oleh Estrada (2001) dalam Rachmiatie (2007) bahwa fokus yang khas dari Radio Komunitas adalah membuat khalayaknya sebagai protagonis (tokoh utama), melalui keterlibatan mereka dalam seluruh aspek manajemen dan produksi programnya, serta menyajikan program yang membantu mereka dalam pembangunan dan kemajuan sosial di komunitas mereka. Tabel 3 memerlihatkan profil dari Radio Komunitas yang menjadi sampel penelitian.

Tabel 3

\section{Profil Radio Komunitas}

\begin{tabular}{|c|c|c|c|c|}
\hline No & Nama Radio & Katagori & Pengelola & Alamat \\
\hline 1. & Zhara Setia FM & Komunitas warga & H. Asep Bobi & $\begin{array}{l}\text { Jl. PPI, No. } 12 \text { Tanjungsari } \\
081321712742 \text { Sumedang }\end{array}$ \\
\hline 2. & STMIK & Komunitas Kampus & $\begin{array}{l}\text { Dady Mulyadi, } \\
\text { M.M. }\end{array}$ & $\begin{array}{l}\text { Jl. Anggrek Situ, No. } 19 \text { Telp. } \\
\text { 081321704666 } \\
\text { Sumedang }\end{array}$ \\
\hline 3. & $\begin{array}{l}\text { Cahaya Swara } \\
\text { Giwangkara SMK } \\
\text { Muhamadiyah }\end{array}$ & $\begin{array}{l}\text { Komunitas Agama/ } \\
\text { Pendidikan Menengah } \\
\text { Atas }\end{array}$ & $\begin{array}{l}\text { Kepala SMK } \\
\text { Muhamadyah } \\
\text { Sumedang }\end{array}$ & $\begin{array}{l}\text { Jl. Dano, No. 88, Kel. Kotakaler. Telp. } \\
\text { 0261-202461 } \\
\text { Sumedang }\end{array}$ \\
\hline 4. & Sungging Galura Rasa & Komunitas Petani & Ir. Nanang Nurasa & $\begin{array}{l}\text { Desa Cilangkap, Kecamatan Buah Dua } \\
\text { Telp. } 081321810582 \\
\text { Sumedang }\end{array}$ \\
\hline 5. & $\begin{array}{l}\text { Sumedang Sehat } \\
\text { Sejahtera Radio Gentra } \\
\text { Pakuwon }\end{array}$ & Komunitas Kesehatan & Dr. Nuroni Hidayat & $\begin{array}{l}\text { Jl. Rd. Suyud } 9 \\
\text { Sumedang }\end{array}$ \\
\hline
\end{tabular}

Sumber: hasil penelitian 2013.

Komposisi dari sampel penelitian di atas mewakili Radio Komunitas dari unsur pendidikan, warga, petani, dan kesehatan. Masing-masing Radio Komunitas tersebut ternyata memunyai program acara yang mengangkat kearifan lokal dari masingmasing komunitas dan juga budaya Sunda yang telah ada secara turum temurun.

\section{Peran Pengelola Radio Komunitas dalam Mengembangkan Siaran Kearifan Lokal}

Fenomena berkembangnya Radio Komunitas di Kabupaten Sumedang, menunjukkan, semangat warga untuk memajukan Radio Komunitas cukup tinggi, keberadaannya dapat bertahan karena semangat antara pengelola, penyiar, dan antusias warga pendengar dalam berpartisipasi untuk kelangsungan siaran komunitas. Ini merupakan konsistensi pengelola memenuhi kebutuhan warga akan informasi dan hiburan yang bernuansa lokal, yaitu mengagendakan acara tentang isu penting dalam komunitas warganya. Untuk pemenuhan kebutuhan informasi warga komunitas tertentu di wilayahnya, walaupun penyajiannya sederhana, namun menjadi format unggulan ketika mendapat sambutan antusias dari warganya. Merupakan pembuktian bahwa kelebihan Radio Komunitas dibanding jenis radio lainnya, yaitu adanya prinsip proximitas atau kedekatan psikologis, fisik, dan budaya (Rachmiatie, 2007). Radio Komunitas yang memunyai target kelompok pendengar pada komunitas tertentu, mengemas program siaran secara kreatif dan konsisten kental dengan nuansa lokal baik dalam sajian informasi maupun hiburan. "Radio Komunitas adalah medium yang memungkinkan masyarakat dalam kalangan terbatas, mengaktualisasikan dirinya melalui program siaran yang dikelola secara bersama-sama" (Wibowo, 2012).

Radio Komunitas sebagai media warga memang memiliki kewajiban untuk memertahankan kearifan lokal yang diwujudkan melalui siaran-siarannya. Data pada tabel 4 memerlihatkan peran dari 
pengelola Radio Komunitas yang menjadi sampel penelitian, dengan memrogramkan siaran yang bernuansa lokal. Penggunaan bahasa lokal seperti bahasa Sunda juga merupakan wujud dari keinginan pengelola untuk mengangkat lokalitas daerah.

Program-program acara tersebut, merupakan acara-acara unggulan dari masingmasing Radio Komunitas, hal tersebut ditunjukkan dengan diberikannya porsi yang dominan untuk acara-acara tersebut, dalam seluruh isi siaran, baik dalam sajian, informasi, pendidikan, dan hiburan. Porsi siaran yang dominan juga ditunjukkan dari durasi masing-masing acara antara satu hingga dua jam. Dominanya acara atau siaran yang bernuansa lokal menunjukkan bahwa pengelola siaran Radio Komunitas berusaha menerapkan asas proximitas (kedekatan psikologis dan geografis) dengan masyarakat setempat. Dengan menyajikan siaran yang bernuansa lokal dan kearifan lokal akan mampu menempatkan Radio Komunitas sebagai bagian dari masyarakat setempat.

Acara atau siaran yang bernuasa lokal memang merupakan keinginan dari warga atau komunitas dari daerah tersebut, karena siaran-siaran lokal tidak pernah didapatkan dari radio sisaran konvensional atau kalau ada pun porsinya sangat kecil. Langkah-langkah yang diambil pengelola untuk mengimplementasikan siaran kearifan lokal adalah; untuk sajian hiburan, menghimpun berbagai seni budaya daerah yang berkembang di Sumedang, juga seni Sunda yang populer di Jawa Barat, dan Provinsi Banten. Acara dikemas secara interaktif, penyiar menerima pertanyaan atau tanggapan warga tentang permasalahan yang dialami atau ditemui, dalam kehidupan sehari-hari di masyarakat.

Tabel 4

Kearifan Lokal dalam Siaran

\begin{tabular}{|c|c|c|c|c|}
\hline Nama Radio & Bentuk Acara & $\begin{array}{c}\text { Durasi Waktu per } \\
\text { hari }\end{array}$ & $\begin{array}{c}\text { Target } \\
\text { pendengar }\end{array}$ & Filosofis Acara \\
\hline Zhara Setia FM & $\begin{array}{l}\text { Sapa warga, wayang } \\
\text { golek, kacapian, } \\
\text { degung jaipong, kecapi } \\
\text { calung, siraman rohani } \\
\text { dalam basa Sunda, } \\
\text { guyonan dalam basa } \\
\text { Sunda. }\end{array}$ & $\begin{array}{l}\text { Masing-masing } \\
\text { hampir } 2 \text { jam } \\
\text { diselingi layanan } \\
\text { masyarakat. }\end{array}$ & Semua usia. & $\begin{array}{l}\text { Memelihara dan } \\
\text { mengenalkan budaya } \\
\text { daerah. }\end{array}$ \\
\hline STIMIK UNSAP FM & $\begin{array}{l}\text { Kantin STIMIK, lagu- } \\
\text { lagu Sunda, kacapian, } \\
\text { degung, Sundanese IT. }\end{array}$ & 2 jam/acara. & $\begin{array}{l}\text { Semua usia tapi } \\
\text { ada acara segmen } \\
\text { khusus } \\
\text { mahasiswa. }\end{array}$ & $\begin{array}{l}\text { Menyampaikan IT } \\
\text { dengan kemasan budaya } \\
\text { lokal. }\end{array}$ \\
\hline $\begin{array}{l}\text { Cahaya Swara } \\
\text { Giwangkara SMK } \\
\text { Muhammadiyah } 1\end{array}$ & $\begin{array}{l}\text { Kuliah Subuh, } \\
\text { Mumuluk, Seni Sunda, } \\
\text { Syariak Layung, } \\
\text { Panglejar Manah, } \\
\text { Dongeng Sunda. Talk } \\
\text { Show. }\end{array}$ & $\begin{array}{l}24 \text { jam siaran, rata- } \\
\text { rata } 1 \text { jam per mata } \\
\text { acara. }\end{array}$ & $\begin{array}{l}\text { Semua usia, pada } \\
\text { acara tertentu } \\
\text { khusus kalangan } \\
\text { muslim dan } \\
\text { siswa. }\end{array}$ & $\begin{array}{l}\text { Mengenalkan, } \\
\text { memelihara seni budaya } \\
\text { daerah. }\end{array}$ \\
\hline $\begin{array}{l}\text { Sungging Galura } \\
\text { Rasa }\end{array}$ & $\begin{array}{l}\text { Info keur warga tani, } \\
\text { ngobrol sore tamba } \\
\text { sare sore-sore, seni } \\
\text { Sunda buhun modern, } \\
\text { wayang. }\end{array}$ & $\begin{array}{l}8 \text { jam siaran } \\
\text { seluruhnya kesenian } \\
\text { Sunda dan informasi } \\
\text { disampaikan dalam } \\
\text { Bahasa Sunda. }\end{array}$ & Semua usia. & $\begin{array}{l}\text { Memelihara, } \\
\text { mengenalkan seni } \\
\text { budaya Sunda dan } \\
\text { tradisi karuhun. }\end{array}$ \\
\hline Gentra Pakuwon & $\begin{array}{l}\text { Kawih Sunda, kacapi } \\
\text { degung, cianjuran, } \\
\text { wayang golek. }\end{array}$ & $\begin{array}{l}\text { Rata-rata } 2 \\
\text { jam/acara. }\end{array}$ & Semua usia. & $\begin{array}{l}\text { Menyampaikan } \\
\text { informasi kesehatan, } \\
\text { pendidikan, ekonomi } \\
\text { melalui kemasan budaya } \\
\text { Sunda. }\end{array}$ \\
\hline
\end{tabular}

Sumber: hasil penelitian 2013. 
Peran pengelola dalam mengembangkan siaran kearifan lokal tidak saja hanya dilakukan di dalam studio rekaman. Tidak jarang pengelola juga menggelar acara off air. Pada acara ini penanggungjawab program siaran berusaha mengakomodasi kepentingan masyarakat sekitar, biasanya dilakukan pada momen ulang tahun radio, atau peringatan
HUT Kemerdekaan RI. Pelibatan masyarakat dan pemerintahan setempat sangat menonjol dalam momen off air. Untuk menyajikan siaran kearifan lokal perlu ditopang dengan sumber daya manusia yang juga memahami apa itu kearifan lokal, agar nantinya mereka juga bisa mengimplementasikannya ke dalam program-program siarannya.

\section{Tabel 5}

\section{Pemahaman tentang Kearifan lokal}

\begin{tabular}{lrl}
\hline No & Nama & \multicolumn{1}{c}{ Jabatan } \\
\hline 1. & H. Asep Bobi & $\begin{array}{l}\text { Pengelola Radio Zhara Setia } \\
\text { Tanjungsari. }\end{array}$
\end{tabular}

2. Dian Fardian

3. Drs. Dadang Setiawan S.Ag

4. Ir. Nanang Nurasa

5. Dr. Nuroni Hidayat Soeriadikusumah

6. Udin Sutisna

7. Recky Junaedi

8. Wawan Gunawan/Dedi Mulyadi

9. Yaya/Engkus

10. Ii Ratiah/Cecep

11. Rosmaya
Pengelola Radio STIMIK UNSAP Jl. Anggrek Situ, Sumedang.

Pengelola Cahya Swara Giwangkara SMK Muhamadiyah Jl. Dano Sumedang.

Pengelola Cahya Swara Giwangkara SMK Muhamadiyah Jl. Dano Sumedang.

Pengelola Sungging Galura Rasa Desa Cilangkap Buah Dua.

Pengelola Radio Gentra Pakuwon, Jl. Rd. Suyud, Sumedang.

Penyiar Radio Zhara Setia Tanjungsari.

\section{Penyiar Radio STIMIK} UNSAP Jl. Anggrek, Sumedang.

Penyiar Radio Cahya Swara Giwangkara SMK Muhamadiyah Jl. Dano Sumedang.

Penyiar Radio Sungging Galura Rasa Desa Cilangkap Buah Dua.

Penyiar Radio Gentra Pakuwon Jl. Rd. Suyud, Sumedang.

\section{Pemahaman tentang Kearifan Lokal}

Kearifan lokal adalah sesuatu yang berkembang di lingkungan masyarakat setempat, pemhaman tersebut kemudian diimplementasikan dalam isi siaran, juga penyampaian oleh penyiarnya.

Kearifan lokal adalah seni budaya masyarakat yang diwariskan secara turun temurun di suatu lingkungan/daerah tertentu.

Kearifan lokal adalah seni atau budaya khas suatu daerah.

Kearifan lokal adalah identitas budaya suatu wilayah, bisa berupa adat istiadat, seni, kepercayaan, dan lainlain.

Kearifan lokal adalah identitas yang tumbuh dan berkembang di suatu daerah dan dipelihara secara terus menerus oleh warga di daerah tersebut.

Kearifan lokal adalah adat istiadat masyarakat di daerah tertentu.

Kearifan lokal adalah kemampuan dari masyarakat setempat untuk memertahankan budayanya sendiri dari budaya luar.

Kearifan lokal adalah kepribadian dari masyarakat setempat yang diwujudkan dalam seni dan tradisi masyarakat setempat.

Kearifan lokal adalah seni dan tradisi masyarakat setempat.

Kearifan lokal adalah adat istiadat dan seni yang berkembang di suatu daerah.

Kearifan lokal adalah seni dan budaya setempat.

Sumber: hasil penelitian 2013.

Tabel 5 menunjukkan, bahwa pengelola maupun penyiar memahami apa itu kearifan lokal. Pada umumnya mereka memahami kearifan lokal sebagai budaya atau seni. 
Bahwa budaya lokal khususnya seni merupakan karya manusia yang di dalamnya mengandung pesan pengetahuan, misalnya pengetahuan bertani, pesan moral, pesan perilaku dalam kehidupan sehari-hari yang tertuang dalam lirik-lirik lagu Sunda, serta adat istiadat yang berkembang yang perlu dikembangkan dan dilestarikan oleh masyarakatnya.

Pengelola Radio Komunitas terus berupaya untuk menyajikan acara atau program siaran agar tetap berkualitas dan memenuhi keinginan dari pendengarnya. Berbagai upaya dilakukan para pengelolanya yakni dengan mencari berbagai informasi baik dari media massa seperti surat kabar, majalah, radio, televisi, buku, maupun melalui tokoh-tokoh masyarakat dan tokoh budaya setempat. Pelibatan terhadap tokoh masyarakat maupun tokoh budaya setempat jelas sesuai dengan karakteristik dari Radio Komunitas, yang menurut Mardin (tanpa tahun) bahwa Radio
Komunitas adalah stasiun siaran radio yang dimiliki, dikelola, diperuntukkan, diinisiatifkan, dan didirikan oleh sebuah komunitas.

Tabel 7 memerlihatkan pengelola radio menetapkan kriteria sumber daya manusia khususnya penyiar harus memahami budaya dan kesenian Sunda, berkarakter nyunda, dan sikap lainnya yang bisa mengakrabkan penyiar dan pendengarnya sesuai dengan segmen pendengar dan segmen acaranya. Hasil penelitian menunjukkan bahwa, penyiar Radio Komunitas yang menjadi informan di Kabupaten Sumedang, tidak ada satu pun yang memunyai kompetensi akademik. Pada umumnya, para penyiar adalah mereka yang ikut merintis pendirian radio dan para pegiat kesenian di daerahnya, dan biasa tampil dalam kegiatan seni juga mengerti musik lainnya selain musik Sunda.

Tabel 6

Sumber Informasi sebagai Pendukung Acara Siaran Kearifan Lokal

\begin{tabular}{|c|c|c|c|c|}
\hline Nama Radio & Nama Acara & Sumber Informasi & $\begin{array}{l}\text { Alat Bantu } \\
\text { Teknis }\end{array}$ & Target Pendengar \\
\hline Zhara Setia FM & $\begin{array}{l}\text { Sapa warga, memutar } \\
\text { lagu Sunda. }\end{array}$ & $\begin{array}{l}\text { Surat kabar, } \\
\text { radio,Televisi, pakar } \\
\text { seni/budaya, majalah, } \\
\text { buku buku. }\end{array}$ & $\begin{array}{l}\text { Kaset, } C D, \\
\text { telepon, } H P \text {, } \\
\text { song request. }\end{array}$ & $\begin{array}{l}\text { Warga masyarakat } \\
\text { Tanjungsari, Nagreg, dan } \\
\text { semua jenjang usia }\end{array}$ \\
\hline STIMIK UNSAP & $\begin{array}{l}\text { Kantin STIMIK, lagu } \\
\text { lagu Sunda, kacapian, } \\
\text { degung, pop Sunda, } \\
\text { Sundanese IT. }\end{array}$ & $\begin{array}{l}\text { Surat kabar, buku buku, } \\
\text { seniman/budayawan, } \\
\text { majalah. }\end{array}$ & $\begin{array}{l}\text { Komputer, } \\
\text { telepon, } C D, \\
\text { telepon, } H P, \\
\text { song request. }\end{array}$ & $\begin{array}{l}\text { Warga masyarakat, } \\
\text { seputar jalan Angrek } \\
\text { sampai daerah Alamsari } \\
\text { Sumedang, usia remaja } \\
\text { /mahasiswa. }\end{array}$ \\
\hline $\begin{array}{l}\text { Cahaya Swara } \\
\text { Giwangkara SMK } \\
\text { Muhamadiyah I } \\
\text { Sumedang }\end{array}$ & $\begin{array}{l}\text { Kuliah subuh, Syariak } \\
\text { layung, Panglejar } \\
\text { manah, Dongeng Sunda, } \\
\text { Talk Show }\end{array}$ & $\begin{array}{l}\text { Surat kabar, buku, } \\
\text { majalah, radio, televisi, } \\
\text { pakar seni/budaya. }\end{array}$ & $\begin{array}{l}\text { Komputer, } \\
\text { telepon, HP, } \\
\mathrm{CD} \text {, kaset, } \\
\text { song request. }\end{array}$ & $\begin{array}{l}\text { Warga masyarakat, } \\
\text { Sumedang Utara, } \\
\text { Tanjungkerta, Ganeas, } \\
\text { semua jenjang usia. }\end{array}$ \\
\hline $\begin{array}{l}\text { Sungging Galura } \\
\text { Rasa }\end{array}$ & $\begin{array}{l}\text { Info keur warga tani, } \\
\text { Ngobrol Sore tamba sare } \\
\text { sore- sore, Seni Sunda } \\
\text { buhun/ modern/ wayang } \\
\text { golek }\end{array}$ & $\begin{array}{l}\text { Majalah, koran, radio, } \\
\text { televisi. tokoh seni/ } \\
\text { budaya. }\end{array}$ & $\begin{array}{l}H P, \\
\text { komputer, } \\
C D / \text { kaset, } \\
\text { song request. }\end{array}$ & $\begin{array}{l}\text { Warga masyrakat } \\
\text { Cilangkap/Cibubuan, } \\
\text { Sekarwangi, Conggeang, } \\
\text { semua jenjang usia. }\end{array}$ \\
\hline Gentra Pakuwon & $\begin{array}{l}\text { Info kesehatan/ } \\
\text { lingkungan, kawih } \\
\text { Sunda, kacapi, degung, } \\
\text { cianjuran, wayang golek }\end{array}$ & $\begin{array}{l}\text { Majalah, koran, buku, } \\
\text { radio, televisi, tokoh } \\
\text { masyarakat/ seni/budaya. }\end{array}$ & $\begin{array}{l}\text { Telepon, } H P \text {, } \\
\text { komputer, } \\
C D \text {, kaset. }\end{array}$ & $\begin{array}{l}\text { Warga masyarakat, } \\
\text { Sumedang Selatan, } \\
\text { Sumedang Utara, Ganeas. }\end{array}$ \\
\hline
\end{tabular}

Sumber: hasil penelitian 2013. 
Tabel 7

SDM Penyiar Siaran Kearifan Lokal

\begin{tabular}{|c|c|c|c|c|}
\hline $\begin{array}{l}\text { Nama } \\
\text { radio }\end{array}$ & $\begin{array}{l}\text { Jumlah } \\
\text { penyiar }\end{array}$ & $\begin{array}{l}\text { Karakter penyiar yang harus } \\
\text { dipenuhi }\end{array}$ & $\begin{array}{l}\text { Kesesuain } \\
\text { dengan } \\
\text { kebutuhan }\end{array}$ & $\begin{array}{l}\text { Komunikasi dengan } \\
\text { warga pendengar }\end{array}$ \\
\hline $\begin{array}{l}\text { Zhara Setia } \\
\text { Fm }\end{array}$ & 4 orang & $\begin{array}{l}\text { Santai, kalem ramah, memiliki } \\
\text { pengetahuan dan wawasan budaya daerah } \\
\text { dan rasa humor, berbahasa dan beraksen } \\
\text { Sunda (nyunda). }\end{array}$ & terpenuhi & $\begin{array}{l}\text { Sangat baik, interaktif } \\
\text { lewat telepon, SMS, dan } \\
\text { surat. }\end{array}$ \\
\hline $\begin{array}{l}\text { STIMIK } \\
\text { UNSAP }\end{array}$ & 4 orang & $\begin{array}{l}\text { Gaul, trendi, menguasai bahasa Sunda } \\
\text { dan nyunda, memiliki pengetahuan yang } \\
\text { cukup, memahami seni budaya daerah. }\end{array}$ & terpenuhi & $\begin{array}{l}\text { Sangat baik, interaktif } \\
\text { melaui telepon, facebook, } \\
\text { dan twitter. }\end{array}$ \\
\hline $\begin{array}{l}\text { Zhara Setia } \\
\quad \text { Fm }\end{array}$ & 4 orang & $\begin{array}{l}\text { Santai, kalem ramah, memiliki } \\
\text { pengetahuan dan wawasan budaya daerah } \\
\text { dan rasa humor, berbahasa dan beraksen } \\
\text { Sunda }(\text { nyunda). }\end{array}$ & terpenuhi & $\begin{array}{l}\text { Sangat baik, interaktif } \\
\text { lewat telepon, SMS, dan } \\
\text { surat. }\end{array}$ \\
\hline $\begin{array}{l}\text { Zhara Setia } \\
\text { Fm }\end{array}$ & 4 orang & $\begin{array}{l}\text { Santai, kalem ramah, memiliki } \\
\text { pengetahuan dan wawasan budaya daerah } \\
\text { dan rasa humor, berbahasa dan beraksen } \\
\text { Sunda }(\text { nyunda). }\end{array}$ & terpenuhi & $\begin{array}{l}\text { Sangat baik, interaktif } \\
\text { lewat telepon, SMS, dan } \\
\text { surat. }\end{array}$ \\
\hline
\end{tabular}

Sumber: hasil penelitian 2013.

\section{PENUTUP}

\section{Simpulan}

Peran pengelola Radio Komunitas dalam mengembangkan siaran kearifan lokal penelitian ini diwujudkan dalam bentuk program-program siaran di Radio Komunitas yang merupakan program siaran unggulan. Program dan bentuk siaran kearifan lokal dalam mengangkat budaya lokal, diwujudkan melalui program siaran yaang disusun dan disajikan dalam suatu mata acara yang dikemas secara kreatif dengan konsep interaktif, mengetengahkan hiburan yang bernuansa Sunda, melalui sajian lagu, kawih, wayang, dan kecapian ciri khas kesenian daerahnya, mendapat apresiasi dari pendengarnya, namun kurang memberi tempat pada kearifan lokal yang dimiliki daerah lainnya, yang bermanfaat sebagai pembanding.

Penguasaan pengetahuan budaya Sunda, mampu berkomunikasi secara nyunda, dan mampu menghibur dan menjadi sahabat bagi pendengarnya, merupakan kualifikasi SDM penyiar yang ditetapkan pengelola, menjadi penunjang dalam meraih pendengar setia radionya agar tetap eksis di masyarakat.
Walaupun penyiar kearifan lokal tidak satupun yang mempunyai latar belakang pendidikan keradioan, namun pengalaman berkesenian dan bermasyarakat menjadi penunjang profesionalisme sebagai penyiar yang betul-betul menguasai karakter lokal.

\section{Saran}

Untuk menunjang sisi ideal tujuan Radio Komunitas disarankan kepada KPID, maupun pemerintah setempat untuk memfasilitasi para pengelola Radio Komunitas memberi pengetahuan tentang pengelolaan radio agar tidak hanya memunyai semangat mendirikan tapi dapat mengerti arah kebijakan dari suatu lembaga penyiaran, dan dapat memahami aspek program, aspek teknis juga aspek manajemen, agar eksistensi radio komunitas dapat betahan dan bermanfaat.

Kehadiran Radio Komunitas warga dalam mengusung isu seni di daerahnya hendaknya tidak hanya untuk memenuhi kepuasan pendengarnya, diharapkan para pengelola dapat menjalankan fungsi radio sesuai harapan publik pedengarnya untuk mendapat pengetahuan tentang kearifan lokal lainnya secara global, dengan penyajian keberagaman konten siaran kearifan lokal, 
untuk memperkaya pengetahuan pendengarnya.

\section{DAFTAR PUSTAKA}

\section{Buku:}

Arifin, Anwar. (1993). Strategi Komunikasi. Bandung: Armico.

Fraser, Colin dan Sonia Estrepo Estrada. (2001). Buku Panduan Radio Komunitas.Jakarta: UNESCO Jakarta Office.

Nazir, Mohammad. (2009). Metode Penelitian. Jakarta: Ghalia.

Rachmiatie, Atie. (2007). Radio Komunitas Eksalasi Demokratisasi Komunikasi. Bandung: PT. Remaja Rosda Karya.

Rosidi, Ayip. (2011). Kearifan Lokal dalam Perspektif Budaya Sunda. Bandung: PT Kiblat Buku Utama.

Sudibyo. (2004). Ekonomi Politik Media Penyiaran. Yogyakarta: LKIS.

Wibowo, Freed. (2012). Tehnik Produksi Program Radio Siaran, Mengenal Medium dan Program Radio Siaran. Jogyakarta: Rona Pancaran Ilmu.

\section{Jurnal:}

Anwari. (2013). Mengembangkan Radio Komunitas Pesantren. Jurnal Komunikasi Islam. Volume 3 No. 2 Tahun 2013, hal.299.

Hakam, Ulil. (2011). Konvergensi Media dalam Radio Komunitas. Jurnal IPTEK KOM ,Vol. 13 No. 1 Tahun 2011, hal. 2.

Juniarta, Hagi Primadasa, Edi Susiloa, dan Mimit Primyastanto. (2013). Kajian Profil Kearifan Lokal Masyarakat Pesisir Pulai Gili Kecamatan Sumber Asik Kabupaten Probolinggo Jawa Timur. Jurnal ESCOFiM, Volume 1 No. 1 Tahun 2013, hal. 12.

Masduki. (2004). Perkembangan dan Problematika Radio Komunitas di Indonesia. Jurnal Ilmu Komunikasi
Volume 1 No. 1, Juni tahun 2004, hal.145.

\section{Prosiding:}

Lilis CH, Dede dan Nova Yuliati. (2012). Mengusung Radio Komunitas sebagai Basis Kearifan Lokal. Prosiding Seminar Nasional Menggagas Pencitraan Berbasis Kearifan Lokal 26 September 2012, Universitas Jenderal Soedirman: Purwokerto. Hal.198.

Nurhidayah. (2011). Proporsionalitas Tayangan Local Wisdom (Kearifan Lokal)Jawa Tengah di Stasiun Televisi Borobudur Semarang. Skripsi. Fakultas Dakwah IAIN Walisongo Semarang. hal.23.

\section{Internet:}

Elisa. (tanpa tahun). Pengertian Kearifan Lokal. Tersedia dalam <elisa.ugm.ac.id/user/archive/download /23627/77357a3c5cf5a1d5be0a8dd078c 13b1f kearifan lokal adalah>.Diakses tanggal 3 Januari 2013.

Fauzia, Ifa Rizty. (2011) .Prediksi Perkembangan Radio Komunitas (Faktor-faktor yang Memengaruhi Perkembangan Radio Komunitas di Yogayakarta dan Solo).Tersedia dalam http://eprints.uns.ac.id/5476/1/2068521 11201110461.pdf. Diakses tanggal 4 Maret 2013.

Mardin. (tanpa tahun). Peran Media Radio Komunitas di Daerah Bencana.Tersedia dalam <http://www.airputih.or.id/wpcontent/plugins/downloadsmanager/upload/peran\%20radio\%20ko munitas.pdf $>$,. Diakses tanggal 3 Maret 2013.

Mumpuni. (2011). Implementasi Regulasi Sistem Stasiun Sun TV Network.Tersedia dalam http://eprints.undip.ac.id/38441/4/Bab_ 3.pdf, diakses tanggal 4 Maret 2013. 